\title{
Improved Communication Skills of Children with Autism Spectrum Disorder using Augmented Reality Based on PECS (Picture Exchange Communication System)
}

\author{
Taryadi $^{1,2}$, Sattriedi Wahyu Binabar ${ }^{2}$ \\ ${ }^{1}$ Departemen of Accounting Computerired, STMIK Widya Pratama, Pekalongan, Indonesia \\ ${ }^{2}$ Departement of Informatic, STMIK Widya Pratama, Pekalongan, Indonesia
}

\begin{abstract}
PECS is a method for developing communication using images to exchange desired objects according to the image, especially for children with autism with non-verbal abilities. PECS has many advantages over other communication learning methods that can encourage autistic children to communicate well. Besides having many advantages, the PECS method itself has many disadvantages. The research conducted was to build an application specifically designed for children with autism by correcting the deficiencies that exist in learning with the PECS method. The application is designed with the guidance of an expert Psychologist Children with Special Needs and refers to previous studies as reference material for application interface design. Application testing involves 4 autistic children from 2 different SLBs. Tests are carried out 2 times for each child to find out the progress of application utilization. The test results show that the proposed application is in accordance with the aesthetic design of the MDA framework that is designed so that it is truly able to be accepted by autistic children while also having a positive impact on them, as well as being able to create a learning environment that is more enjoyable both for children with autism and for teachers.
\end{abstract}

Index Terms_- PECS, Augmented Reality and alternative communication, Autism Spectrum Disorder.

\section{Introduction}

Autism is a disease that inhibits the development of children's cognitive function, social skills, and communicative abilities with Autism Spectrum Disorder (ASD) (Mesibov, Adams, \& Klinger, 2013). In general, autistic children learn something easier using visual techniques rather than verbal or verbal instructions. One visual method that can help autistic children in communicating is PECS (Picture Exchange Communication System). PECS is a method for developing communication with autistic children using images to exchange desired objects according to the image. In the research conducted (Charlop-Christy, Carpenter, Le, LeBlanc, \& Kellet, 2002) proved that the use of PECS has successfully improved social communication behavior and reduced behavioral problems in autistic children. Although it has many advantages, the PECS method also has several problems. Learning to use PECS manually requires a book that must be carried everywhere, besides that it requires a large number of drawing cards to find out what the autistic child feels and wants, and some additional cards to add vocabulary to autistic children. In practice some of these cards are not infrequently lost, damaged, or not carried away, making it difficult for autistic children to look for images that they want. Delays in finding appropriate images create a communication gap between autistic children and their companions.
In recent years, parents and therapists have been less interested in traditional solutions such as PECS [3]. In line with this, mobile technologies are being recommended by therapists as AAC devices (Augmentative and alternative communication) [4]. AAC is a form of communication using cues, pictures, or electronic devices to replace verbal or written words in helping people to share their thoughts. A systematic review of 15 studies on the use of mobile devices concluded that mobile devices were successfully used to target communication skills [5]. In addition, in the study [6] proved that the frequency of communication of autistic children using mobile devices tends to be the same or even higher than traditional PECS.

From this background, it is necessary to develop a communication learning application using the mobile-based PECS method so that learning is more fun and practical if you have to move around. The proposed application, designed with guidance from education experts and practitioners of children with special needs to understand the needs of the target group and produce applications that are suitable for them. The main contributions of this study are: application design development that can improve interactive and dynamic communication skills, creating a learning environment that is more innovative and fun, and in accordance with the needs of autistic children.

The remainder of the research carried out is structured as follows: Section 2 describes the position and contribution of research conducted on several studies and applications that have existed before. Section 3 presents the application 
development process. Section 4 discusses the results of the application development process. Finally, Section 5 deals with the discussion of the results achieved for the target group.

\section{Research Methodology}

The development method used in making this application is to use a prototype method, where the stages include: (1) design, (2) implementation, (3) use, and (4) evaluation. The development process is iterative, where after arriving at the evaluation stage it is possible to repeat the development process from the design stage. In each initial process a prototype will be produced, and in the next iteration process will be produced an improvement of the prototype generated in the previous process flow.

In this section, some design concepts are explained to provide a better learning environment in accordance with the needs of the target group, namely:

a. Interface: The interface is designed simply, without a lot of visual stimuli, to maximize the chance of concentration, understanding and learning from the players. Autistic children love predictable and consistent environments. Small changes in the environment can cause them to become stressed and cause emotional outbursts. Then the application must have consistency both in font selection, button placement, etc.[15]. Interface design in this application is designed with the guidance of an expert Psychologist Children with Special Needs. In addition to consulting with experts, the development of this mobile application interface refers to recommendations [16], ("Mobile Application Accessibility Handbook.," N.d.). The recommendations are summarized and used according to the learning environment of the target group as follows:

1) Menu navigation and buttons are built consistently and simply;

2) Images or symbols can help to identify the purpose of navigation / key, and can reduce the cognitive load of users;

3) Warning or feedback should not be lost as long as the user does not respond;

4) Background sound can help users that the application still works when in passive mode;

5) Applications must have high contrast between text and background;

6) The choice of language style should be concise, simple and clear;

7) The number of functions, and navigation must be limited to avoid cognitive overload.

b. Environmental Configuration: Every autistic child has certain characteristics and skills the proposed application allows various configurations to suit the needs of each player. For children who cannot read, the text features of the application can be disabled. For non-verbal children, can use images and audio where this feature can be adjusted. Table 1 presents all possible configurations.

Table 1.

all possible configurations

\begin{tabular}{llc} 
& \multicolumn{2}{c}{ Konfiguration } \\
\hline A. & Text & On/Off \\
B. & Audio & On/Off \\
\cline { 1 - 1 } C. & Tutorial & Yes/No \\
\hline
\end{tabular}

c. Communication: Picture Exchange Communication System (PECS). The proposed application is based on special images developed for children with communication disorders. Children with limited communication can communicate creating sentences by selecting images that represent objects and actions. Bondy and Forst [17] explain that there are 6 phases in the PECS method:

1) Phase I. This phase aims to enable the child to be able to observe the items/objects presented, the child selects one picture from the item, picks up and hands over to the teacher or mentor.

2) Phase II. In this phase the child is able to change the communication partner and submit the picture to the hands of his communication partner.

3) Phase III. In phase III it is expected that the child is able to ask for the object he wants by moving towards the communication board then selecting a particular image that represents his desire and submitting the image to the teacher or communication partner.

4) Phase IV The fourth phase aims to enable the child to ask for the desired object with or without an image of the object accompanied by the use of a multi-word phrase while opening the drawing compilation book, then taking the picture "I want" or "I want", then the picture is placed on the sentence board, then the child takes a picture of the desired object and puts it to the right of the "I want" symbol. At the end of this phase, it is expected that children can use 20-50 images to communicate and communicate with various partners.

5) Phase V. In this phase the child is able to spontaneously request the desired object through an image and can answer with a picture of the question "What do you want?"

6) Phase IV This phase is the last phase of the PECS method so that it is expected that in this phase the child is able to comment, express feelings, likes and dislikes. 
d. Quiz: Quiz is found in each phase. This quiz serves to determine the user in continuing the learning phase. Answer choices on quizzes must be designed with a small amount to reduce the level of user difficulty [19]. Determining the number of answers to quiz answers in this application is determined from the interview process with experts and SLB autistic teachers. The question is designed not to change until the user successfully answers the question correctly. While feedback on quizzes is designed not to use images or negative words, according negative feedback in response to failure can reduce the motivation of autistic children to continue the game and reduce learning potential.

e. Visual Objects: Autistic children have limitations in thought and attention. With pictures / visuals they can learn more easily. The image in this application can issue the name of the object so that it can facilitate learning and can provoke the child's attention. Images are designed as closely as possible with real images to make it easier for autistic children to recognize the object. In addition, each image object is equipped with audio that was previously performed by the sound recording process. This voice recording process is also guided by an expert so that the intonation and pronunciation can be well received by autistic children.

f. Prototype Design: The prototype system design in this study is using the handheld device method on an Android mobile device. Handheld devices on Android devices are chosen because they are flexible devices that can provide a real-time and personalized learning environment. The Handheld method proves to be a useful tool to help students of all ages be more involved in various learning activities processes

\section{Results and Analysis}

\subsection{Application Architecture}

Application architecture is designed using the HIPO diagram. The following is an explanation of the design of the HIPO diagram in the proposed application:

a. Main Menu 0.0. Is the initial menu page when the application is run. This page consists of 7 sub menus, namely Phase I menu, Phase II menu, Phase III menu, Phase IV menu, Phase V menu, Phase VI menu and Exit menu.

b. Phase I 1.0. This page displays classrooms menu, dining room menu, bathroom menu, bedroom menu, playground menu and quiz menu.

c. Classroom 1.1. This page shows the background and objects in the classroom.

d. Dining Room 1.2. This page shows the background and objects in the dining room. e. Bathroom 1.3. This page shows the background and objects in the bathroom.

f. Playground 1.4. This page shows the background and objects on the playground.

g. Bedrooms 1.5. This page shows the background and objects in the bedroom.

h. Quiz 1.6. This page displays a quiz matching images that are similar to the picture of the question.

i. Phase II 2.0. This page displays Phase II learning.

j. Phase III 3.0. This page resembles a page in Phase II, only has more objects than phase II

k. Phase IV 4.0. This page displays the menu I want, the menu I feel and the menu I see

1. I Want 4.1. This page displays several image objects and example sentences related to desires.

m. I feel 4.2. This page shows some image objects and example sentences related to feeling.

n. I see 4.3. This page shows several image objects and example sentences related to objects that can be seen.

o. Phase V 5.0. This page displays a quiz to determine what is seen, what is felt and what is desired based on a condition.

p. Phase VI 6.0. This page shows many objects to express what you want

q. Exit 7.0. The exit page is notified whether the user wants to exit or not, with the selection button yes and no.

Figure 1 Shows the Hipo Diagram of the proposed application.

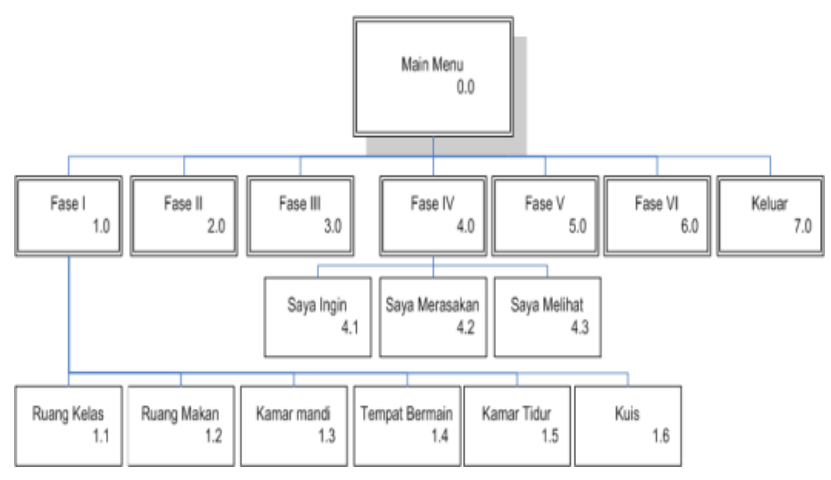

Fig. 1. HIPO Diagram of the proposed application

\subsection{Application Program}

\subsubsection{Main Menu Page}

The main menu is the first page that will appear in the application. In this menu there are 8 buttons, namely Phase I, Phase II, Phase III, Phase IV, Phase V, Phase VI, about and exit. The main page can be seen in Figure 2. 


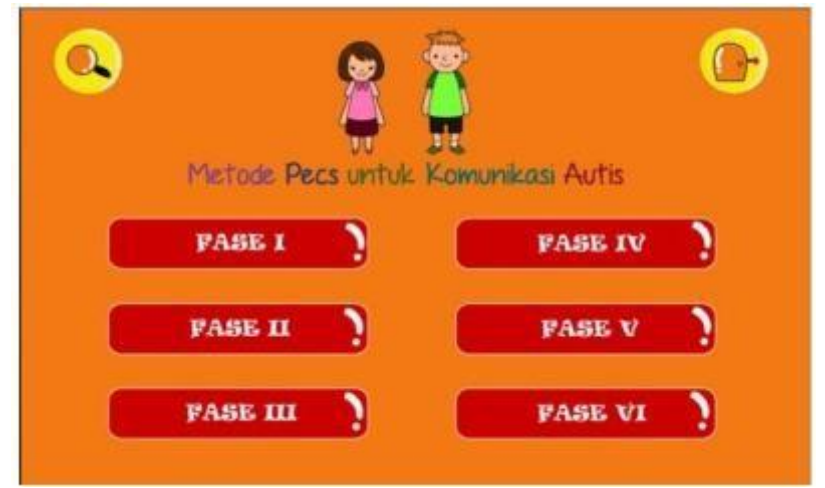

Fig. 2. Main Menu Page Display

\subsubsection{Phase I page}

Phase I is a phase of observing items / objects in several environments. Phase I page has 8 buttons, namely the classroom button, dining room, bathroom, playground, bedroom, quiz, tutorial and the back button to the main page. Phase I page views are shown in Figure 3.

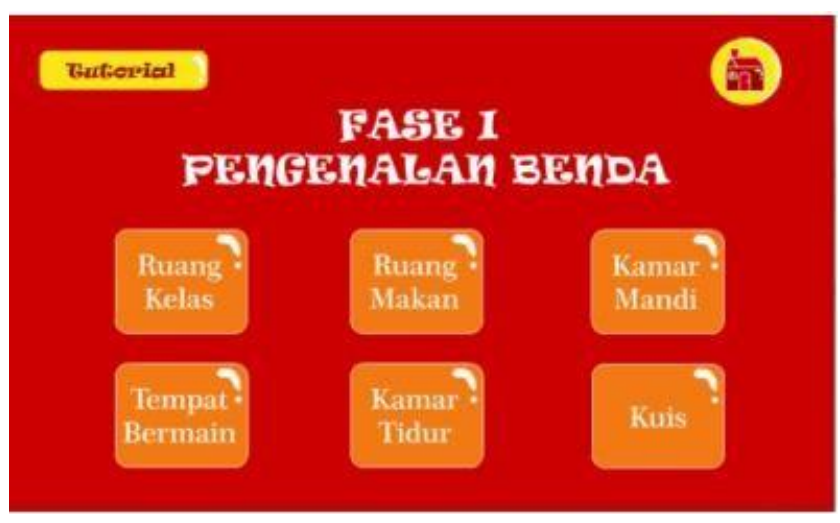

Fig. 3. Display of Phase I Pages

\subsubsection{Classroom Room, Dining Room, Courtyard and Bedroom}

The classroom page displays pictures of objects in the classroom. On this page every object is a button. The object that is pressed will produce sound according to the name of the object being pressed. The class room page has a phase I button that functions back to the phase I page, in addition there is a next button that functions to go to the next room. Figure 4 is a page view of the classroom.

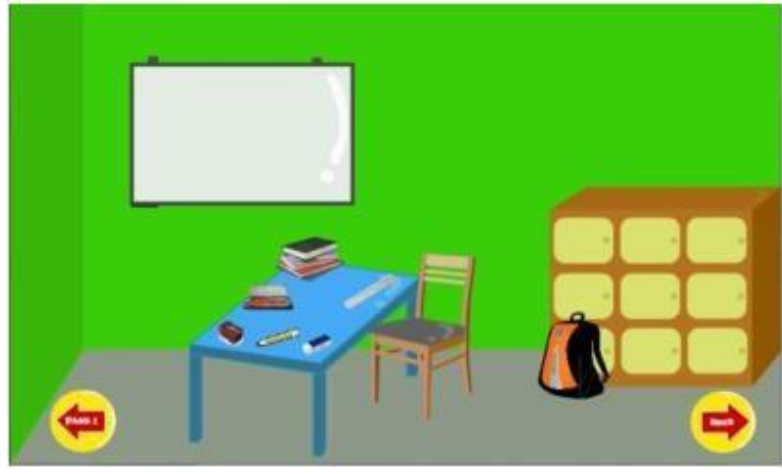

Fig. 4. Page Display of Classroom

The dining room page appears after pressing the dining room button on the Phase I page. Or after pressing the next button on the classroom room. Display of dining room can be seen in figure 5 .

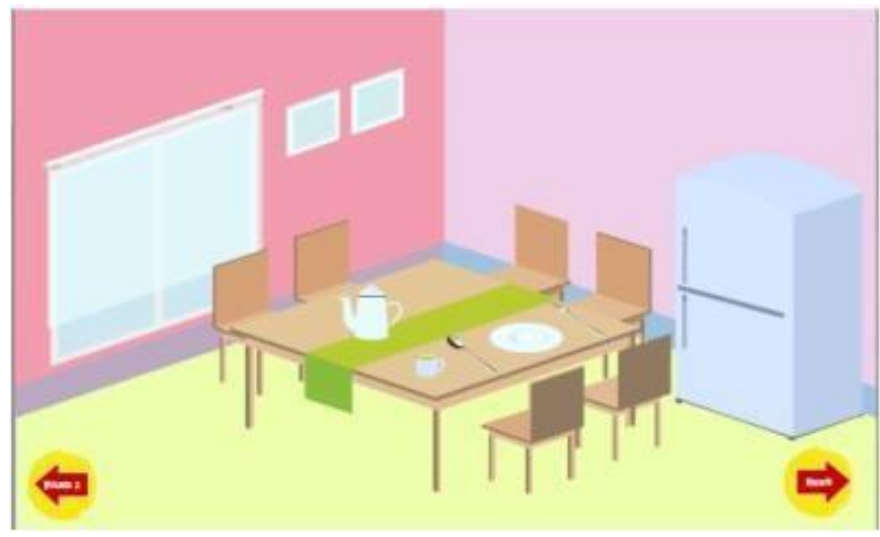

Fig. 5. Display of Dining Room Pages

The playground page appears when pressing the play button located on the Phase I page. The page view of the playground can be seen in Figure 6 .

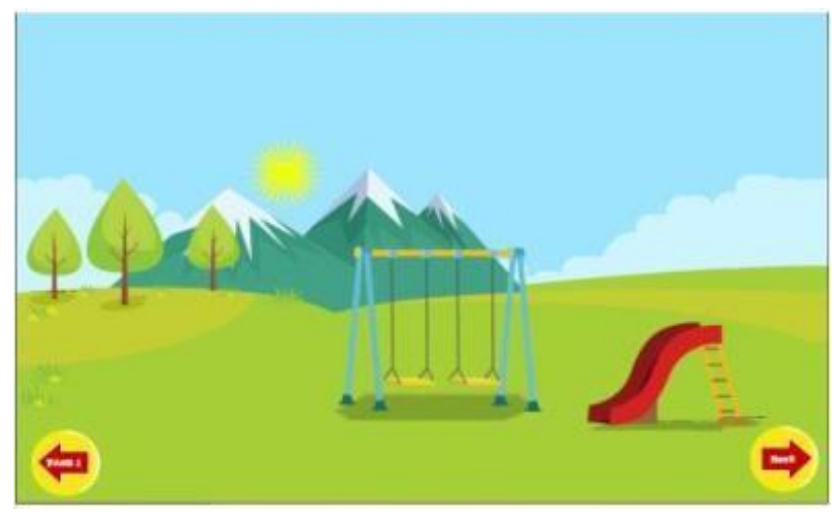

Fig. 6. Display of Playground Pages

\subsubsection{Quiz page}

Phase I quiz page shows 10 image questions. The user is tasked with pressing the image that matches the image problem. Quiz page can be seen in figure 7. If the user 
presses the correct image, the popup will come out correctly with the picture of the smiley character and the correct sound. If it's wrong then popups come out with vibrant character images and sound can certainly.

Phase II is the phase of submitting images to the communication partner. The phase II quiz page displays a quiz that resembles quiz I only the process uses drag and drop function. On the phase II page there is a target box that functions to check whether the image is dropped correctly or not. Phase II pages can be seen in figure 8 .

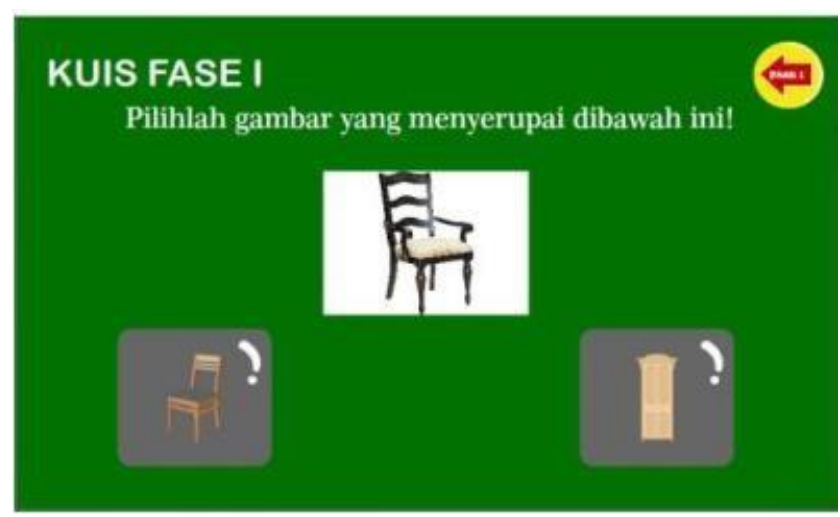

Fig. 7. Display of Phase I Quiz Pages

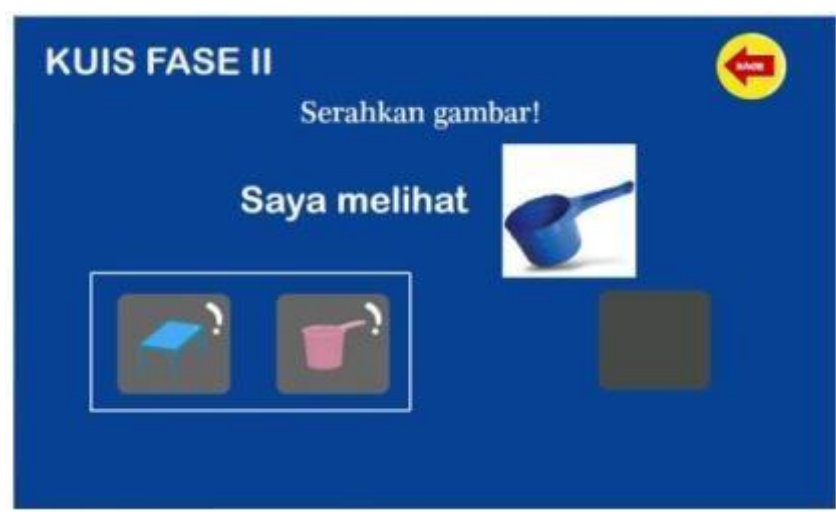

Fig. 8 Display of Phase II Quiz Pages

\subsection{DISCUSSION}

\subsubsection{Observation Testing}

After the application is complete, the next step is to test whether the proposed application is truly capable of being accepted by autistic children, while giving a positive impact on them. The test was carried out on four autistic children from two autistic SLBs in Pekalongan with different behaviors and limitations. For the record, all children involved in this study have received approval from the parents of each child, and related SLB. Autistic children chosen as respondents are those who are able or familiar with smartphones/gadgets, because not all autistic children are able to use the media. Tests were carried out twice for each child. Following are the characteristics of these children: r. The first respondent is male with education level in grade 5 elementary school. First respondent was 12 years old. The first respondent was able to communicate verbally even though it was not smooth.

s. The second respondent is female with a grade 5 education in elementary school and is 12 years old. The second respondent communicates non-verbally.

t. The third respondent is male with education level in grade 4 elementary school. Third respondent is 11 years old. Third responders communicate non-verbally.

u. The fourth respondent is male with a grade 5 education in elementary school and is 12 years old. The fourth respondent communicates nonverbally.

Figures 9, 10, 11, and 12, show the respondents tested.

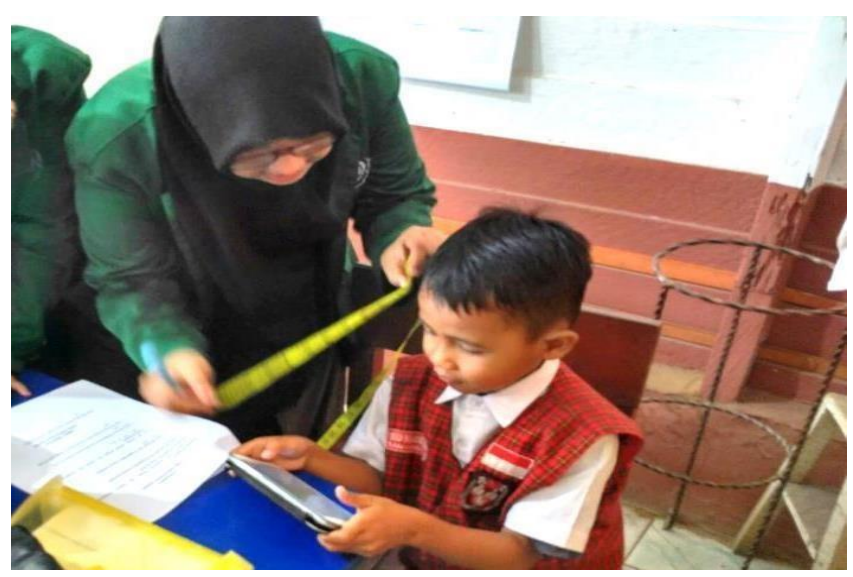

Fig. 9. First Respondent

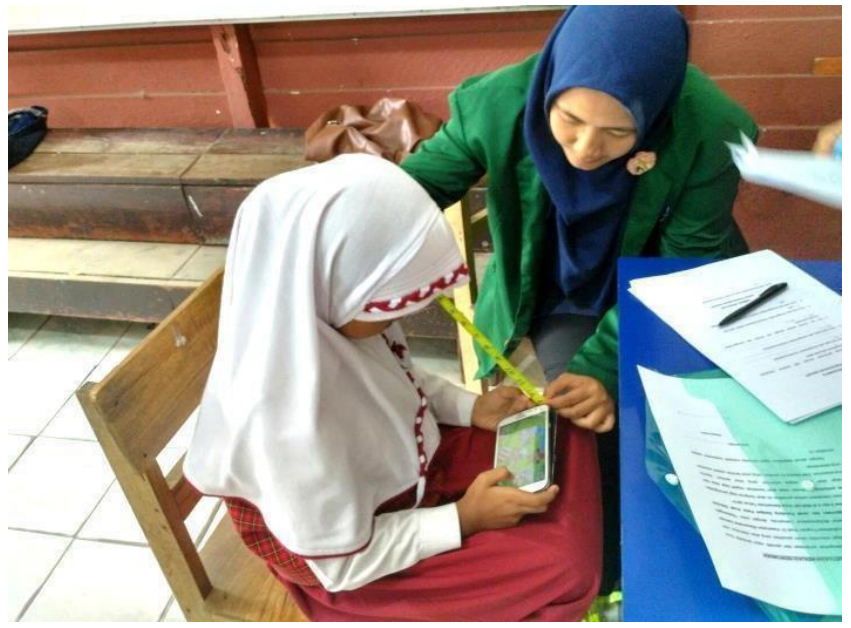

Fig. 10. Second Respondent 


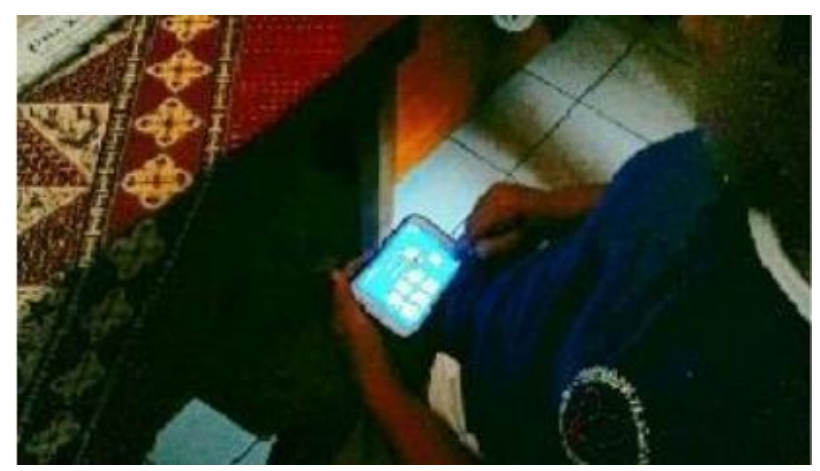

Fig. 11. Third Respondent

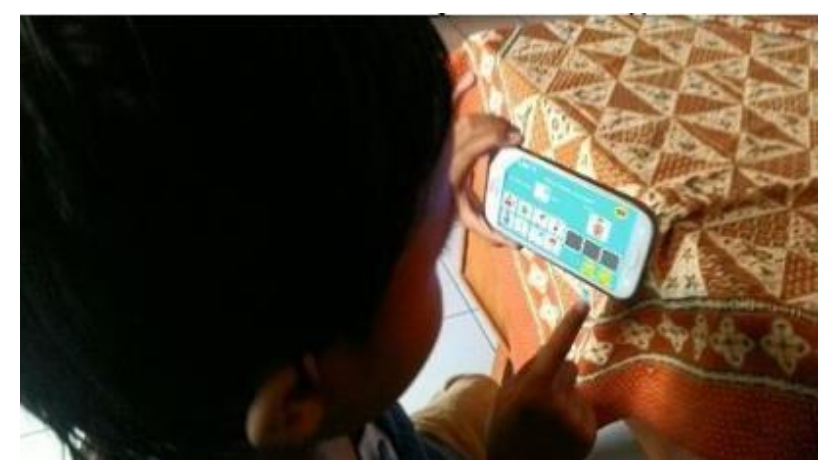

Fig. 12. Fourth Respondent

The testing session was conducted in a special room with two teachers/assistants accompanying an autistic child, and one researcher recorded a trial session in one session. This testing session on average takes 5-15 minutes to adjust the willingness and involvement of autistic children in this testing session. The results of the video recording were then tested to an expert Psychologist Children with Special Needs. The assessment category of the test with this observation method is seen from the respondent's gestures and gestures when using this application to determine the level of interest and involvement of respondents (autistic children) in using this application. The assessment category consists of how many respondents look to the mentor or teacher, verbal disinterest, gesture/gesture disinterest, verbal attraction, gesture/gesture attraction, and celebration. What category of respondents saw the stands needed to know how much the level of interaction between respondents and their companions. In this test the expert will observe and calculate the number of assessment criteria mentioned earlier through video recordings taken from the testing session.

Verbal attraction can be observed from the number of times the respondent speaks positively to the application. Verbal disinterest can be seen from whether the respondent issued a rejection word when playing. Gesture interest is seen from actions such as: smiling, laughing, and showing other attraction gestures according to the characteristics of the respondent. Gesture disinterest can be either putting the device, biting a finger, or refusing to use the application. Furthermore, interaction with the companion is the intensity of the respondent seeing and talking with the companion. Interaction with companion is important for autistic children who are less able to interact socially. Celebration can be in the form of hand flapping, say "right" every time you answer correctly, do "highs" with a companion, and other meaningful celebrations.

The following Figure 13 shows a graph of the first respondent's test results.

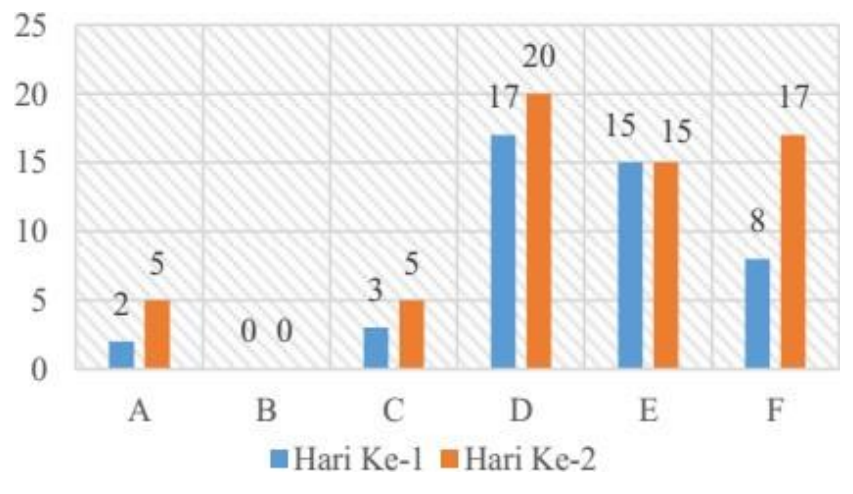

Fig. 13. Testing of First Respondents

Testing on the first day, the first respondent was very enthusiastic about using this application. There were two times looking at the teacher, gesture disinterest was seen 3 times, verbal interest 17 times, non-verbal attraction 15 times, and celebrations 8 times. On the second day the respondent was happy to run the application when recognizing objects. There are 5 times looking at the short. There is no verbal disinterest. Seen 5 times frowning. Verbal interest 20 times. Bodybuilding interest 15 times. And celebration when running the quiz is 17 times. Then the second respondent was tested. The following Figure 14 shows the results of testing on the second respondent. Second responders are quieter and smarter using smartphones. The second respondent communicated nonverbally so that he rarely made a sound during the testing session. Seeing one person or teacher as much as one time, 4 times disinterest in body movements, 8 times bodily attraction and 4 celebrations. On the second day, the respondent saw the stands as much as 2 times, looked frowned as much as 1 time, interested in body movements 15 times, celebrated 16 times. Then the third respondent was tested.

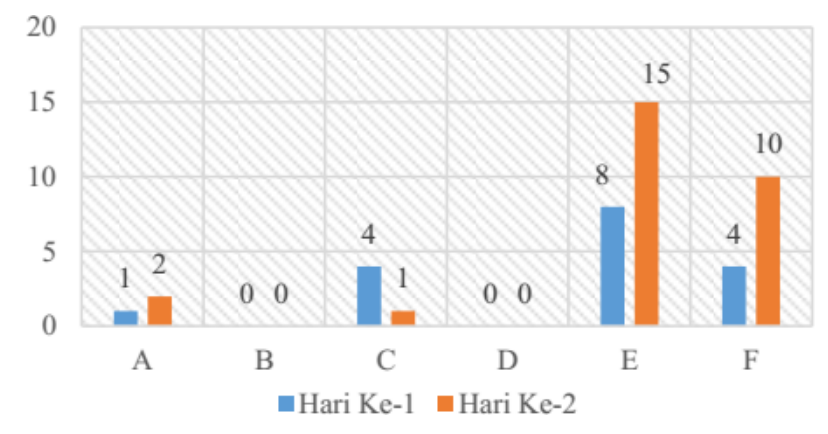

Fig. 14. Graph of Testing of Second Respondents 
The following Figure 15 shows the results of testing on the third respondent:

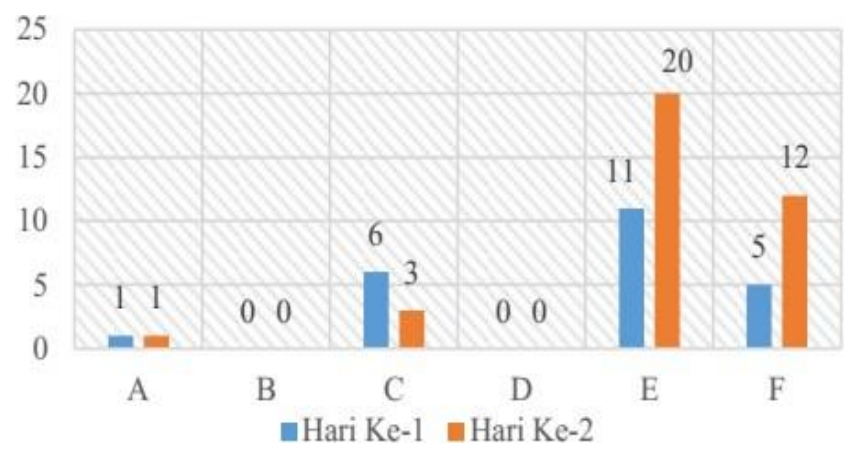

Fig. 15. Graph of Testing of Third Respondents

The third respondent communicated nonverbally so that he rarely made a sound during the testing session. Seeing one person or teacher as much as one time, 6 times disinterest in body movements, 11 times bodily attraction and 5 celebrations. On the second day, the respondent saw 1 stature, 3 times non-verbal disinterest, 20 times gestures, 12 celebrations.

Finally, the fourth respondent was tested. The fourth respondent is proficient and used to using a smartphone. The fourth respondent communicates nonverbally, while the testing session does not even sound. The fourth respondent saw three or three chapters, 5 times disinterest in body movements, 12 times bodily interest and 11 celebrations. On the second day, the respondent saw the stands 5 times, 2 times disinterest in body movements, 14 times verbal interest, 18 movements in body gesture, 22 celebrations. Figure 16 shows a graph of the fourth respondent's test.

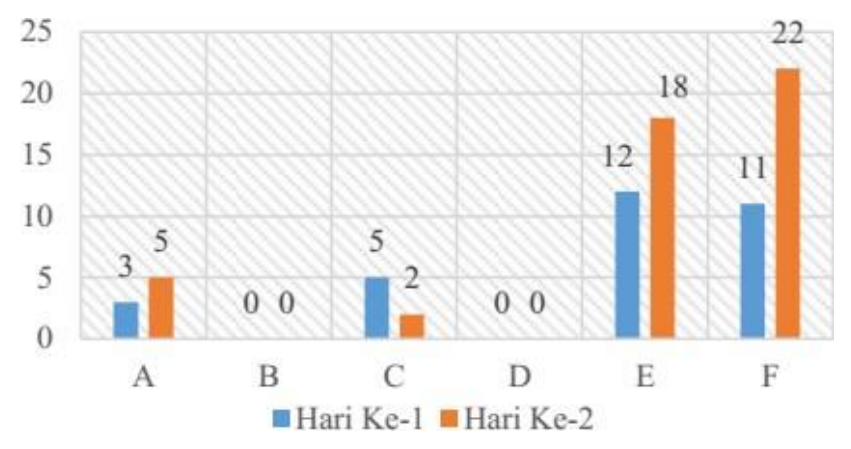

Fig. 16. Graph of Testing of Fourth Respondent

From the observational test results above it can be concluded that, the application developed has the potential as an easy medium of learning communication and can actively involve users in a fun learning process. Simple features and navigation, allowing all users to operate this application easily, although some must be helped. From the test results, 4 respondents showed interest in using this application.

This was indicated by the high value of both verbal and non-verbal interests. The high level of celebrations confirmed that the applications developed were able to involve respondents in more enjoyable learning. Finally, there was an increase in looking at the companion from the first and second day, showing the creation of communication between autistic children and mentors.

\subsubsection{Interview Testing}

Application testing was also carried out by interviewing 10 teachers in the two SLBs used in this study. From the results of the interview, it can be concluded that this application is very interesting, moreover there is the introduction of objects using visual and sound, this helps for children with autism, because most people with autism better understand visual than verbal, besides the content that is used can easily be understood. The application used is also in accordance with the PECS method taught at school.

Furthermore, testing with interview methods was also carried out on practitioners and psychologist experts handling special needs children. From the results of interviews with experts and practitioners it can be concluded that the application is in accordance with the PECS method [19]. Visual use is considered very helpful in learning to children with autism because autistic sufferers are easier to understand visually than verbal. Then, in the object recognition feature there is the sound of the object's name pronunciation, this certainly helps to give an understanding to autistic children about the names of objects, but it is feared that the child cannot name the object, this is because there is no visualization of mouth motion to teach. Furthermore, it is also necessary to be given additional features that can make the learning companion (teacher) more involved in this application, so that the child continues to interact with people not only with the application.

\section{Conclusion}

In this study an application was designed for autistic children learning to communicate with the PECS method. Application design uses MDA framework that focuses on stimulating the development of communication and interaction skills, namely: challenge, discovery and fellowship. The test results show that the proposed application is in accordance with the aesthetic design proposed by MDA framework so that it is truly able to be accepted by autistic children, while giving a positive impact on them. Although the testing process showed satisfactory results, but as further research needs to be tested to a larger and varied target group so that it accommodates most of the possibilities of the behavior of different autistic children. In addition, from interviews with experts and practitioners handling special needs children shows the need to have a mouth motion visualization feature to say the names of objects, and additional features that can make the learning companion (teacher) more involved in this application. 


\section{Acknowledgement}

The research is supported and funded by Research Directorate and Society Dedication of General Directorate of Research Reinforcement and The Development of Research Ministry, Technology, and Higher Education in year 2018.

Researcher also send best gratitude to the teachers of the inclusion school in Pekalongan City, Pekalongan Regency, Pemalang Regency that have supported a lot in this research. The aknowledgement also raise to the parents of ASD child that permit the researcher in doing the treatment of PECS method with augmented reality multimedia based to improve the communication ability. To all parties that helped in collecting data, data calculation, researcher team that support in all process of the research.

\section{References}

[1] Mesibov, G. B., Adams, L. W., \& Klinger, L. G. (2013). Autism: Understanding the disorder. Springer Science \& Business Media.

[2] Charlop- Christy, M. H., Carpenter, M., Le, L., LeBlanc, L. A., \& Kellet, K. (2012). Using the picture exchange communication system (PECS) with children with autism: Assessment of PECS acquisition, speech, social communicative behavior, and problem behavior. Journal of Applied Behavior Analysis, 35(3), 213-231.

[3] Sulzer-Azaroff, B., Hoffman, A. O., Horton, C. B., Bondy, A., \& Frost, L. (2009). The Picture Exchange System (PECS): What do the data say? Focus on Autism and Other Developmental Disabilities, 24(2), 89-103.

[4] Light, J., \& McNaughton, D. (2012). Supporting the communication, language, and literacy development of children with complex communication needs: State of the science and future research priorities. Assistive Technology, 24(1), 34-44.

[5] Kagohara, D. M., Meer, L. van der, Ramdoss, S., O’Reilly, M. F., Lancioni, G. E., Davis, T. N., Sigafoos, J. (2013). Using iPods ${ }^{\circledR}$ and iPads $®$ in teaching programs for individuals with developmental disabilities: A systematic review. Research in Developmental Disabilities, 34(1147-156.)

[6] Flores, M., Musgrove, K., Renner, S., Hinton, V., Strozier, S., Franklin, S., \& Hil, D. (2012). A comparison of communication using the Apple iPad and a picture-based system. Augmentative and Alternative Communication, 28(2), 74-84.

[7] Moore, M., \& Calvert, S. (2010). Brief Report: Vocabulary Acquisition for Children with Autism: Teacher or Computer
Instruction. Journal of Autism and Developmental Disorders, 30(4), 359-362.

[8] Anwar, A., Rahman, M. M., Ferdous, S. M., \& Ahmed, S. I. (2011). A computer gamebased approach for increasing fluency in the speech of the autistic children. In 11th IEEE international conference on Advanced Learning Technologies (ICALT), 2011 (pp. 17-18).

[9] Frutos, M., Bustos, I., Zapirain, B. G., \& Zorrilla, A. M. (2011). Computer game to learn and enhance speech problems for children with autism. In 16th international conference on Computer Games (CGAMES) (pp. 209-216). IEEE.

[10] Bosseler, A., \& Massaro, D. W. (2013). Development and evaluation of a computer-animated tutor for vocabulary and language learning in children with autism. Journal of Autism and Developmental Disorders, 33(6), 653-669.

[11] Coleman-Martin, M. B., Heller, K. W., Cihak, D. F., \& Irvine, K. L. (2015). Using computer-assisted instruction and thenonverbal reading approach to teach word identification. Focus on Autism and Other Developmental Disabilities, 20(2), 80-90.

[12] Hailpern, J., Karahalios, K., \& Halle, J. (2009). Creating a Spoken Impact: encouraging vocalization through audio visual feedback in children with ASD. In Proceedings of the 27th International Conference on Human Factors in Computing Systems, CHI 2009 (pp. 453-462.). Boston, MA, USA.

[13] Hetzroni, O. E., \& Tannous, J. (2014). Effects of a ComputerBased Intervention Program on the Communicative Functions of Children with Autism. Journal of Autism and Developmental Disorders, 34(2), 95-113.

[14] Whalen, C., Liden, L., Ingersoll, B., Dallaire, E., \& Liden, S. (2016). Behavioral Improvements Associated with ComputerAssisted Instruction for Children with Developmental Disabilities. The Journal of Speech and Language Pathology, 1(1), 11-26.

[15] Madsen, M., Kaliouby, R. el, Eckhardt, M., Hoque, M. E., Goodwin, M. S., \& Picard, R. (2009). Lessons from participatory design with adolescents on the autism spectrum. In CHI 2009 (pp. 3835-3840). ACM Press.

[16] Mariger, H. (2006). Cognitive Disabilities and the Web: Where Accessibility and Usability Meet? Retrieved January 23, 2016, from http://ncdae.org/resources/articles/cognitive/

[17] Taryadi, Kurniawan, Ichwan, (2017). The improvement of autism spectrum disorders child communication ability with PECS method Multimedia Augmented Reality based, Journal of Physics: Conference Series, Series. 947

[18] Frost, L., \& Bondy, A. (2012). The Picture Exchange Communication System training manual. (2nd ed.). Cherry Hill, NJ: Pyramid Educational Consultants.

[19] Tincani, M. (2014). Comparing the picture exchange communication system and sign language training for children with autism. Focus on Autism and Other Development Disabilities, 19(3), 152-163. 